\title{
Cross-sectional study on the relationship between therapeutical education and self-monitoring of blood glucose
}

\author{
Studiu transversal asupra relaţiei dintre cunoştinţele furnizate de educaţia \\ terapeutică şi barierele în calea automonitorizării glicemiei
}

Alina Delia POPA, Ileana ANTOHE

Disciplina Nursing, Universitatea de Medicină şi Farmacie „Gr.T. Popa“, Iaşi, România

\begin{abstract}
REZUMAT
Educația terapeutică privind automonitorizarea glicemiei este deosebit de importantă pentru că se corelează cu valoarea hemoglobinei glicate ( $\mathrm{Hb} \mathrm{A1c}$ ) şi are ca obiectiv prevenirea dezvoltării complicațiilor diabetului zaharat.

Obiective. S-a realizat un studiu transversal în scopul de a evalua relația dintre nivelul cunoştințelor privind automonitorizare glicemiei şi frecvența determinării acesteia de către pacienți.

Material şi metode. Studiul transversal, la care au participat 150 pacienți, s-a realizat prin aplicarea unui număr de trei chestionare care au vizat obținerea de informații privind frevența testării, barierele in calea determinării glicemiei la domiciliu şi nivelul de educație privind utilizarea glucometrului şi interpretarea datelor rezultate.

Rezultate şi discuții. Toți pacienții au declarat că îşi testează singuri glicemia. Majoritatea pacienților au declarat că se testează o dată pe zi $(58 \%)$ sau innainte de fiecare masă. Am remarcat corelații semnificative ale scorului total obținut la chestionarul de cunoștințe şi nivelul barierelor în calea testării $(p=0,037)$, precum şi cu frecvența testării glicemiei $(p=0,046)$.

Concluzii. Nivelul de cunoştințe privind necesitatea testării glicemiei, tehnica acesteia şi interpretarea datelor obținute s-au corelat pozitiv cu frecvența automonitorizării.
\end{abstract}

Cuvinte cheie: automonitorizarea glicemiei, educație terapeutică, diabet zaharat

\footnotetext{
ABSTRACT

Self-monitoring of blood glucose is particularly important for its correlation with the value of glycated hemoglobin $(\mathrm{Hb} \mathrm{A1c})$ in order to prevent the development of complications of diabetes.

Purpose. A cross-sectional study was conducted to evaluate the relationship between the level of self-monitoring blood glucose knowledge and the frequency of its determination.

Material and method. We conducted a study in a sample of 150 patients, which consisted in applying three questionnaires. The aim was to obtain information on the frequency of blood glucose testing, the barriers and the level of education on the use of the glucometer and the interpretation of the resulting data.

Results and discussion. All patients tested their blood glucose themselfs. Most patients declared they tested it once a day (58\%) or before each meal. We noticed significant correlations of the total score obtained in the
} 
knowledge questionnaire and the level of barriers to testing $(p=0.037)$, as well as the frequency of blood glucose determinations $(p=0.046)$.

Conclusions. The level of knowledge about the necessity of blood glucose determination, its technique, and the interpretation of the data obtained positively correlated with the frequency of self-monitoring.

Keywords: self-monitoring blood glucose, therapeutical education, diabetes

\section{INTRODUCERE}

Controlul optim al valorilor glicemiei previne sau întârzie dezvoltarea complicaţiilor cronice specifice diabetului zaharat şi reprezintă unul dintre obiectivele terapeutice majore. Aplicarea de la început a tratamentului intensiv şi realizarea unui control optim al valorilor glicemiei previn pe termen lung dezvoltarea complicaţiilor cronice (memorie metabolică) (1).

Educaţia terapeutică a pacientului cu diabet zaharat are ca obiective informarea pacientului asupra caracterului cronic al bolii, implicarea acestuia în tratament, inducerea capacităţi şi deprinderilor de autocontrol. Pacienţilor li se cer motivaţie, instruire şi implicare în controlul bolii (2).

Automonitorizarea glicemiei este definită prin determinarea repetată a glicemiei cu ajutorul glucometrului, în scopul furnizării informaţiilor necesare modificării tratamentului pentru atingerea obiectivelor terapeutice (3). Explicarea a rolulului şi scopului tehnicii automonitorizării aparţine cadrului educaţiei specifice a pacientului cu diabet zaharat (4). Există argumente care susţin că autocontrolul corect se corelează cu scăderea hemoglobinei glicate ( $\mathrm{Hb} \mathrm{A1c}$ ), deci cu gradul controlului glicemic (5).

În acest context, educaţia terapeutică privind automonitorizarea este deosebit de importantă, iar evaluarea cunoştinţelor pacienţilor constituie o etapă majoră a evaluării periodice în ambulator.

\section{OBIECTIVE}

S-a realizat un studiu transversal pe un eşantion de 150 de pacienţi internaţi în Ambulatorul Clinicii Diabet, Nutriţie şi Boli Metabolice a Spitalului Clinic de Urgenţe "Sfântul Spiridon“ din laşi, în cursul anului 2016, în scopul de a evalua relaţia dintre nivelul cunoştinţelor privind automonitorizare glicemiei şi frecvenţa determinării acesteia de către pacienţi.

\section{MATERIALE ŞI METODE}

Studiul s-a realizat prin aplicarea unui număr de trei chestionare după obţinerea consimţămân- tului informat al pacienţilor, cu acordul conducerii Clinicii Diabet, Nutriţie şi Boli Metabolice.

Primul chestionar a vizat o serie de date generale privind caracteristicile demografice: vârsta (ani); mediul de provenienţă (urban/ rural); sex; stare civilă; numărul de clase absolvite; angajarea în câmpul muncii; tipul şi durata diabetului; prezenţa complicaţiilor cronice; dar şi date legate de frecvenţa determinării glicemiei (mai rar de o dată pe zi; o dată pe zi; de 2-3 ori pe zi; înainte de fiecare masă; înainte şi la 2 ore după masă sau numai când simt că este o problemă). Pacientii au fost invitaţi să răspundă la întrebări care au avut ca obiectiv evaluarea cunoştinţelor privind definiţia automonitorizării, dacă îşi determină singuri sau cu ajutor, glicemia.

Cel de-al doilea chestionar a inclus un număr de 23 de întrebări cu răspuns multiplu care au vizat noţiuni legate tehnica determinării glicemiei şi care a fost completat direct de către participanţi pentru a nu le influenţa răspunsurile.

Al treilea chestionar a urmărit identificarea motivelor care împidică pacienţii să se testeze, fiind un chestionar validat tradus din limba engleză (6). Pacientii au completat direct răspunsurile la întrebări.

Pentru prelucrarea statistică a datelor s-a utilizat programul SPSS (Statistical Package for Social Sciences) versiunea 13.0 pentru Windows (Chicago, IL, USA).

Pentru evaluarea gradului de asociere între variabile s-au determinat coeficienţii de corelaţie Spearman rho. Testul chi-pătrat $\left(\chi^{2}\right)$ a fost utilizat pentru compararea variabilelor nominale, iar analiza de varianţă (ANOVA) pentru a aprecia măsura în care două sau mai multe grupuri au medii diferite.

\section{REZULTATE}

Studiul a inclus un număr de 150 de pacienţi având o vârstă cuprinsă între 33 şi 85 de ani (în medie de 60.68 ani), dintre care $56 \%$ au fost de sex masculin. Lotul a cuprins un număr de $63,6 \%$ persoane din mediul urban. Majoritatea pacienţilor au avut studii liceale $(57,1 \%)$ sau au absolvit mai puţin de 8 clase $(38,1 \%)$. Numai $22 \%$ dintre persoanele studiate au fost salariate, restul fiind pensionate $(76 \%)$. 
În ceea ce priveşte tipul de diabet, $8 \%$ au avut DZ tip1, iar 82\% DZ tip 2, cu o durată medie a bolii de 6,79 ani. Un procent de 16,9\% dintre pacienţi nu au prezentat complicaţii cronice specifice diabetului, $40 \%$ au fost diagnosticaţi cu polineuropatie periferică senzitivomotorie, $14 \%$ cu retinopatie diabetică, iar $2 \%$ cu nefropatie. Dintre pacienţi, un procent de $2 \%$ au avut atât complicaţii neuropatice, cât şi microangiopatice oculare şi renale.

Toţi pacienţii au declarat că îşi testează singuri glicemia. Majoritatea pacienţilor au declarat că se testează o dată pe zi (58\%) sau înainte de fiecare masă. Un număr relativ mare de pacienţi (15\%) au declarat că îşi testează glicemia doar atunci când simt că este o problemă (tabelul 1).

TABELUL 1. Frecvenţa determinării glicemiei

\begin{tabular}{|l|c|c|}
\hline \multirow{2}{*}{} & \multicolumn{2}{|c|}{$\begin{array}{c}\text { de câte ori vă testaţi } \\
\text { valoarea glicemiei }\end{array}$} \\
\cline { 2 - 3 } & Nr. & $\%$ \\
\hline Mai rar de 1/zi & 15 & $30,0 \%$ \\
\hline $1 /$ zi & 14 & $28,0 \%$ \\
\hline $2-3 /$ zi & 4 & $8,0 \%$ \\
\hline Înaint aremasă & 9 & $18,0 \%$ \\
\hline Numai când este o problemă & 8 & $16,0 \%$ \\
\hline
\end{tabular}

Pentru evaluarea barierelor în calea testării s-a aplicat un chestionar validat constituit din 7 întrebări ce au vizat motivele pentru care pacienţii au evitat să-şi teteze glicemia (tabelul 2).

Astfel, $51.02 \%$ au declarat că sunt deranjaţi de faptul că nu obţin o picătură suficient de mare pentru a fi aplicată ceea ce i-a determinat să evite testarea glicemiei. În schimb, $44.9 \%$ dintre pacienţi au declarat că au evitat să-şi testeze glicemia pentru că trebuie să stoarcă pulpa degetului pentru a obţine o picătură de sânge, iar $12,24 \%$ dintre persoanele evaluate evită deseori să-şi determine glicemia din acest motiv. Lipsa vatei a împiedicat
$12,24 \%$ dintre persoanele evaluate să se testeze deseori sau foarte frecvent, iar pe $24,49 \%$ ocazional. Numai 34,69\% dintre pacienţi au declarat că nu li s-a întâmplat niciodată să se testeze pentru că nu au vată la ei. Durerea resimţită la înţepare a fost o barieră importantă în calea automonitorizării, numai $28,57 \%$ dintre pacienţi au declarat că nu li s-a întâmplat niciodată să se testeze din acest motiv. $57,14 \%$ dintre pacienţi au evitat să se testeze frecvent din cauza senzaţiei permanente de durere pe care o resimt la nivelul degetelor. Înţeparea repetată pentru a obţine o picătură suficientă de sânge, a constituit un motiv puternic care să împiedice testarea glicemiei pentru pacienţi, 24,49\% dintre aceştia au declarat că li s-a întâmplat ocazional să evite să-şi determine glicemia din acest motiv (tabelul 2).

Cu toate că majoritatea participanţilor au declarat că îşi testează glicemia şi că o determină singuri, a existat un număr de semnificativ de persoane care evită deseori sau foarte frecvent să-şi determine glicemia din cauza fricii de a se înţepa singuri (tabelul 2).

Pentru analiza barierelor în calea testării, răspunsurile furnizate de pacienţi au fost notate de la 1 la 5 pornind de la frecvenţa niciodată la foarte frecvent, cu cât suma fiind mai mare cu cu cât au existat bariere mai importante în calea testării. Astfel punctajul minim posibil a fost de 7, iar cel maxim de 35. Media obţinută în lotul analizat a fost de 15,59, cu deviaţia standard de 4,66. Coeficientul de fidelitate internă a chestionarului (Cronbach's alpha) a fost de 0,712.

Evaluarea cunoştinţelor privind automonitorizarea s-a realizat cu ajutorul unui chestionar care a cuprins întrebări care au evaluat cunoştinţe privind frecvenţa testării şi interpretarea rezultatelor obţinute; noţiunile privind codificarea aparatului şi pregătirea pentru realizarea testării; semnifica-

TABELUL 2. Bariere în calea testării glicemiei - analiza descriptivă

\begin{tabular}{|c|c|c|c|c|c|}
\hline \multirow[b]{2}{*}{ Motive } & \multicolumn{5}{|c|}{ Frecvența testării \% } \\
\hline & $\begin{array}{c}\text { Numai când este } \\
\text { o problemă }\end{array}$ & $\begin{array}{c}\text { Mai rar de } \\
1 / z i\end{array}$ & $1 / z i$ & \begin{tabular}{|c|} 
Înainte de fiecare \\
masă
\end{tabular} & $\begin{array}{l}\text { Înainte şi la } 2 \text { ore } \\
\text { după fiecare masă }\end{array}$ \\
\hline $\begin{array}{l}\text { Nu obţin o picătur tă } \\
\text { de sânge \% }\end{array}$ & 42.86 & 51.02 & 6.12 & & \\
\hline Stoarcerea pulpei degetului \% & 24.49 & 12.24 & 44.9 & 18.37 & \\
\hline Lipsa vatei \% & 34.69 & 28.57 & 24.49 & 10.2 & 2.04 \\
\hline $\begin{array}{l}\text { Durerea degetelor ce } \\
\text { împiedică desfăşurarea } \\
\text { ăţiß̨br c }\end{array}$ & 28.57 & 30.61 & 12.24 & 24.49 & 4.06 \\
\hline $\begin{array}{l}\text { Necesitatea de a se înţepa de } \\
\text { mai multe ori\% }\end{array}$ & 24.49 & 28.57 & 24.49 & 20.31 & 2.04 \\
\hline $\begin{array}{l}\text { Senzaţia de pernă cu ace a } \\
\text { degetelor \% }\end{array}$ & 34.69 & 22.45 & 28.57 & 6.13 & 8.16 \\
\hline Frica de înţepătură \% & 43.9 & 24.49 & 14.29 & 12.14 & 4.08 \\
\hline
\end{tabular}


ţia valorilor HI (>600 mg/dl) şi Lo (<20 mg/dl) şi a gestiunii acestor situaţii; circumstanţele în care se recomandă testarea suplimentară a glicemiei (efortul fizic, semne sugestive de hipoglicemie; prezenţa intoleranţei digestive şi afecţiunile intercurente, febra). Ultimele întrebări au realizat o evaluare a cunoştinţelor privind ţintele controlului glicemic (tabelul 3).

Atribuind un scor de 1 răspunsurilor corecte şi de 0 celor incorecte şi totalizând scorurile realizate la fiecare întrebare de fiecare pacient s-a obţinut un scor total, care a avut o valoare medie de 9,53, cu deviaţia standard de 2,69 (tabelul 3). S-a testat fidelitatea internă a chestionarului, obţinând o valoare a Cronbach's alpha de 0,687.

Am remarcat corelaţii semnificative între scorul total obţinut la chestionarul de cunoştinţe şi nivelul barierelor în calea testării (tabelul 4).

\section{DISCUȚII}

În eşantionul pe care I-am selectat, toţi pacienţii au declarat că îşi testează singuri glicemia. Deşi majoritatea pacienţilor au declarat că se testează o dată pe zi, doar câţiva participanţi au declarat că îşi determină glicemia înainte de fiecare masă.

La procesul de automonitorizare a glicemiei contribuie mai mulţi factori, cum ar fi nivelul de educaţie, fondul cultural, credinţele şi priorităţile personale, capacitatea de a răspunde la emoţii negative (7). Studii recente au sugerat că pacienţii cu diabet zaharat tip 2 care dispun de un nivel ridicat de educaţie şi de abilităţi cognitive legate de planificarea şi rezolvarea problemelor au şanse mai mari de a integra eficient automonitorizarea în stilul de viaţă (8). Aceste abilităţi au prezis un control mai bun al valorilor glicemiei, dar, în acelaşi timp, s-au corelat cu frecvenţa mai redusă a perioadelor de hiperglicemie şi a numărului de hipoglicemii (9). Cu toate acestea, există date care au sugerat că mulţi pacienţi găsesc dificilă integrarea automonitorizării în viaţa de zi cu zi. Mai mult decât atât, mulţi pacienţi găsesc că modalitatea practică de a aplica şi adapta automonitorizarea la cerinţele zilnice nu este suficient explicată pentru a fi aplicată la condiţiile cotidiene (10).

TABELUL 3. Chestionar evaluare cunoştinţe privind automonitorizarea glicemiei

\begin{tabular}{|c|c|c|c|c|c|c|c|}
\hline \multirow{2}{*}{ Nr. } & \multirow{2}{*}{ Item } & \multicolumn{4}{|c|}{ Alternative de răspuns \% } & \multicolumn{2}{|c|}{ \% răspunsuri } \\
\hline & & 1 & 2 & 3 & 4 & Corecte & Incorecte \\
\hline 1. & Frecvenţa test & 12,2 & 36,7 & 46,9 & 4,1 & 46,9 & 53,1 \\
\hline 2. & Frecvenţa testării - injecţia unică & 28,6 & 38,8 & 14,3 & 18,4 & 28,6 & 71,4 \\
\hline 3. & Determinarea glicemiei de dimineaţă - rol & 6,1 & 59,2 & 26,5 & 8,2 & 59,2 & 40,8 \\
\hline 4. & Determinarea glicemiei de seară - rol & 14,3 & 28,6 & 26,5 & 30,6 & 28,6 & 71,4 \\
\hline 5. & Determinarea glicemiei la culcare - rol & 28,6 & 38,8 & 12,2 & 20,4 & 38,8 & 61,2 \\
\hline 6. & omplet-de & 14,3 & 32,7 & 38,8 & 14,3 & 38,8 & 61,2 \\
\hline 7. & Pregă e母înaintea testării & 10,2 & 20,4 & 42,9 & 26,5 & 42,9 & 57,1 \\
\hline 8. & area perioadei de valabilitate a testelor & 16,3 & 40,8 & 22,4 & 20,4 & 40,8 & 59,2 \\
\hline 9. & $\begin{array}{c}\text { V area codului glucometrului - înaintea începerii } \\
\text { este ? }\end{array}$ & 14,3 & 34,7 & 44,9 & 6,1 & 44,9 & 55,1 \\
\hline 10. & $\begin{array}{l}\text { V area codului glucometrului - înaintea începerii } \\
\text { este ? }\end{array}$ & 12,2 & 53,1 & 26,5 & 8,2 & 53,1 & 46,9 \\
\hline 11. & $\begin{array}{l}\text { Introducerea testului în aparat se face - înaintea } \\
\text { obţinerii picăturii }\end{array}$ & 81,6 & 8,2 & 6,1 & 4,1 & 8,2 & 91,8 \\
\hline 12 & Pentru obţinerea picăturii de insulină - pregă e? & 8,2 & 67,3 & 20,4 & 4,1 & 67,3 & 32,7 \\
\hline 13 & $\begin{array}{l}\text { Pentru obţinerea picăturii de insulină - schimbarea } \\
\text { acului }\end{array}$ & 28,6 & 20,4 & 20,4 & 30,6 & 28,6 & 71,4 \\
\hline 14 & Valoarea $\mathrm{HI}$ a tă de glucome & 12,2 & 24,5 & 8,2 & 55,1 & 55,1 & 44,6 \\
\hline 15 & Dacă pe aparat este a tă valoarea HI - conduită & 24,5 & 36,7 & 22,4 & 16,3 & 24,5 & 75,5 \\
\hline 16. & Valoarea Lo a tă de glucome & 44,9 & 24,5 & 18,4 & 12,2 & 44,9 & 55,1 \\
\hline 17. & Valoarea Lo-decizie ter & 34,7 & 24,5 & 18,4 & 22,4 & 24,5 & 75,5 \\
\hline 18 & Testarea glicemiei - ef & 22,4 & 24,5 & 4,1 & 49 & 22,4 & 77,6 \\
\hline 19. & Testarea glicemiei - semne de hipoglicemie & 14,3 & 69,4 & 4,1 & 12,2 & 69,4 & 30,6 \\
\hline 20. & Testarea glicemiei - semne de cetoza & 81,6 & 20,4 & 46,9 & 4,1 & 81,6 & 18,4 \\
\hline 21. & Testarea frecventă - situaţii speciale & 28,6 & 20,4 & 46,9 & 4,1 & 20,4 & 79,6 \\
\hline 22. & $\begin{array}{l}\text { Testarea glicemiei - prevenţie complicaţii acute şi } \\
\text { cronice }\end{array}$ & 17 & 17 & 16,3 & 14,3 & 34,7 & 65,3 \\
\hline 23 & Valoarea recomandată a glicemiei de dimineaţă & 22,4 & 32,7 & 18,4 & 26,5 & 26,5 & 73,5 \\
\hline 24 & Valoarea recomandată a glicemiei la 2 ore după masă & 32,7 & 22,4 & 16,3 & 28,6 & 22,4 & 77,6 \\
\hline
\end{tabular}


TABELUL 4. Corelaţii ale scorului chestionarului de evaluare a cunoştinţelor

\begin{tabular}{|l|c|c|}
\hline & $r$ & $p$ \\
\hline $\begin{array}{l}\text { Corelaţia scorului ches } \\
\text { cunoş ţॄ cu barierele în calea testării }\end{array}$ & $-0,28$ & 0,037 \\
\hline $\begin{array}{l}\text { Corelaţia scorului ches } \\
\text { cunoş ţॄ cu frecvenţa testării }\end{array}$ & 0,18 & 0,046 \\
\hline
\end{tabular}

Persoanele implicate în îngrijirea pacienţilor cu diabet zaharat trebuie să ia în considerare percepţia pe care o au pacienţii asupra rolului testării glicemiei, dar şi emoţiile şi durerea asociate cu automonitorizarea. Costul testelor şi impactul financiar la nivelul individului şi al familiei nu trebuie, de asemenea, neglijate (11).

În studiul nostru, principalele bariere în calea testării frecvente a glicemiei au fost frica de durere, senzaţia de pernă de ace şi necesitatea de a se înţepa repetat în pulpa degetului. Barierele în calea automonitorizării au fost identificate în studii cantitative observaţionale. În acestea, un rol important I-au avut vârsta avansată, nivelul redus de educaţie, statutul economic scăzut, numărul comorbidităţilor asociate, frica de durerea asociată testării, lipsa suportului din partea medicilor (12). În studiile calitative, s-au identificat numeroase motive care ar constitui un obstacol în calea determinării glicemiei la domiciliu, cum ar fi emoţiile şi gândurile negative, durerea pulpei degetelor, descurajarea produsă de obţinerea unor valori inadecvate ale glicemiei, lipsa de conştientizare a efectelor hiper- sau hipoglicemiei, lipsa suportului social, precum şi incapacitatea de a interpreta rezultatele obţinute prin automonitorizare (13).
Chiar atunci când nu există bariere financiare în calea procurării testelor de glicemie, frecvenţa testării nu este cea aşteptată. Astfel, în Suedia, mai puţin de 50\% dintre pacienţi îşi măsoară glicemia de 4 ori pe zi sau mai des. Acest rezultat indică necesitatea stimulării suplimentare a pacienţilor, programele online şi dezvoltarea unor dispozitive mai uşor de folosit considerându-se a fi benefice (14).

În studiul nostru, nivelul de cunoştinţe privind tehnica testării şi interpretarea rezultatelor furnizate de aceasta s-au corelat invers cu barierele în calea testării. $O$ corelaţie slabă, dar semnificativă s-a remarcat şi între nivelul de cunoştinţe privind automonitorizarea şi frecvenţa testării glicemiei.

Alte studii au arătat că educaţia pacienţilor şi dezvoltarea unor abilităţi legate de rezolvarea problemelor şi setarea unor obiective standardizate ar putea contribui la îmbunătăţirea complianţei pacienţilor. Terapia comportamentală şi interviul motivaţional ar putea constitui modalităţi practice care să ajute pacienţii cu diabet în atingerea scopurilor terapeutice propuse (15).

\section{CONCLUZII}

Educaţia pacienţilor cu diabet zaharat este o component importantă a tratamentului. Îmbunătăţirea nivelului de cunoştinţe privind necesitatea testării glicemiei, tehnica acesteia şi interpretarea datelor obţinute au efecte benefice asupra automonitorizării.

Conflict of interest: none declared Financial support: none declared

\section{BIBLIOGRAFIE}

1. American Diabetes Association. Diagnosis and Classification of Diabetes Mellitus. Diabetes Care, Vol 34, 2019; S(1):62-69.

2. Schnell O, Barnard K, Bergenstal R, Bosi E, Garg S, Guerci B, Haak T. Clinical Utility of SMBG: Recommendations on the Use and Reporting of SMBG in Clinical Research Diabetes care 2015; 38, 1626-1633.

3. Weinstock RS, Braffett BH, McGuigan P, Larkin ME, Grover NB, Walders-Abramson N, [...] TODAY Study Group. Self-Monitoring of Blood Glucose in Youth-Onset Type 2 Diabetes: Results From the TODAY Study. Diabetes Care, 2019; 42(4): https://doi. org/10.2337/dc18-1854.

4. Shen Y, Zhu W, Lu L, Lu F, Kan K, Bao Y, Zhou J. Contribution of structured self-monitoring of blood glucose to self-efficacy in poorly controlled diabetes patients in China Diabetes Metab Res Rev. 2019; 35:e3067 https://doi.org/10.1002/ dmrr.3067

5. Willems S, De Maesschalck S, Deveugele M, Derese A, De Maeseneer J. Socioeconomic status of the patient and doctor-patient communication: does it make a difference? Patient Educ Couns 2005; 56(2):139-146.

6. Vrijhoef $\mathrm{HJ}$, Hubertus $\mathrm{KH}$, Groenier P, Kleefstra A, Van der Bijl N, Jaap N. Development and Validation of the Perception of Self-Monitoring of Blood Glucose Scale in Insulin-Treated Patients With Diabetes. Journal of Nursing Measurement. 2015; 57-71. doi 10.1891/1061-3749.23.1.57.

7. Ward JEF, Stetson BA, Mokshagundam SL. Patient perspectives on self-monitoring of blood glucose: perceived recommendations, behaviors and barriers in a clinic sample of adults with type 2 diabetes. J Diabetes Metab Disord. 2015; 14: 43.

8. Primozic S, Tavcar R, Avbelj M, Dernovsek MZ, Oblak MR. Specific cognitive abilities are associated with diabetes selfmanagement behavior among patients with type 2 diabetes. Diabetes Res Clin Pract. 2012; 95:48-54. doi: 10.1016/j. diabres.2011.09.004.

9. Wang JZ, Janice Matthews JT, CharronProchownik D, Sereika SM, Siminerio L. Self-monitoring of blood glucose is associated with problem-solving skills in hyperglycemia and hypoglycemia. Diabetes Educ. 2012; 38(2):207-214. doi: 10.1177/0145721712440331

10. Ong WM, Chua SS, Ng CJ. Barriers and facilitators to self-monitoring of blood 
glucose in people with type 2 diabetes using insulin: a qualitative study Patient Prefer Adherence. 2014; 8: 237-246.

11. Hortensius J, Kars MC, Wierenga WS, Kleefstra N, Bilo HJ, van der Bijl JJ. Perspectives of patients with type 1 or insulin-treated type 2 diabetes on self-monitoring of blood glucose: A qualitative study. BMC Public Health. 2012; 12:167-177.

12. Lind M, Svensson AM, Rosengren A. Glycemic control and excess mortality in type 1 diabetes. N Engl J Med 2015; 372:880-881.

13. Moström $P$, Ahlén $E$, Imberg $\mathrm{H}$ et al. Adherence of self-monitoring of blood glucose in persons with type 1 diabetes in Sweden. BMJ Open Diabetes Research and Care 2017; 5:e000342.

14. Robson J, Smithers H, Chowdhury T et al. Reduction in self-monitoring of blood glucose in type 2 diabetes: An observational controlled study in east
London. Br J Gen Pract 2015; 65(633):e256-63.

15. Parsons SN, Luzio SD, Harvey JN, Bain SC, Cheung WY, Watkins A, Owens DR. Effect of structured self-monitoring of blood glucose, with and without additional TeleCare support, on overall glycaemic control in non-insulin treated Type 2 diabetes: The SMBG Study, a 12-month randomized controlled trial. Diabetic Medicine, 2019; 00:1-13. https://doi. org/10.1111/dme.13899 